\title{
Research of Benefit Distribution Mechanism of Steel Logistics Resources Integration Based on Cooperative Game
}

\author{
Fan Yuqing* and Ju Songdong
}

School of Economics and Management, Beijing Jiaotong University, Beijing, 100044, China

\begin{abstract}
At present, the scattered and closed steel logistics resource should be integrated. Reasonable benefit allocation mechanism is the prerequisite for steel logistics resources integration. Based on previous studies on steel logistics resource integration, this paper proposes an important problem in steel logistics resources integration: benefit distribution. First, this paper gives the classification of steel logistics resources, analyzes the characteristic of steel logistics resources, and proposes connotation of steel logistics resources integration. Second, this paper gives analysis of steel logistics resources integration based on cooperative game, proposes the three principles and three influence factors of benefit distribution in steel logistics resources integration, establishes benefit distribution model based on Shapley value. At last, This paper verifies the feasibility of the above theory and the method by a case study.
\end{abstract}

Keywords: Benefit distribution, cooperative game, resources integration, steel logistics.

\section{INTRODUCTION}

China is one of the largest steel producer and steel consumer in the world. With the development of steel industry, steel logistics industry is rising. The scale of steel logistics is large. At present, steel logistics industry exits some outstanding problems, such as irrational allocation and homogeneous competition. Especially, steel production enterprises, steel trading enterprises and steel sales enterprises in the steel supply chain construct a large number of steel logistics parks. The lack of effective coordination between steel logistics parks leads to steel logistics resources idle. Therefore, steel industry logistics resources need to be integrated.

In the actual operation of the steel supply chain, some enterprises are carrying on logistics resources integration. For example, on one hand, steel production enterprises establish specialized logistics sector to integrate internal logistics resources. On the other hand, steel production enterprises construct steel information transaction platform to integrate internal and external logistics resources. Therefore, from the development of steel industry and the demand of enterprises, it is necessary to study deeply on steel logistics resources integration problems theoretically so as to guide the enterprise actual operation, promote the linkage of steel industry and logistics industry and achieve a win-win situation of steel industry and logistics industry.

Relevant studies of steel logistics resources integration are mainly in the following aspects. The studies of Cui, Sui and Dong focus on regional logistics resources integration [1-3]. Some studies give some mathematical models to solve the related problems [4-8]. Wang [9] gives the development strategy to strengthen resources integration and enhance extension service capacity of steel supply chain. Jia [10] studies the agility of SLSSC from the perspective of the Supply-Hub of integrated logistics services. Jin [11] proposes LSSC mode based on supply chain collaboration, analyzes the establishment methods of cooperation mechanism among steel supply chain enterprises. Xiong [12] proposes to build cloud business platform by the combination of cloud computing and e-business, does the analysis to the effect of its application in the enterprise to prove the feasibility of the model.

From the domestic and foreign relevant studies, it is can be seen that the researches on steel logistics resources integration are lack of targeted studies, and the studies focus on mode, content and information. Meanwhile, most perspectives of studies on logistics resources integration are from the perspective of logistics service provider. They are lack of thought which considered logistics supply side and demand side as a whole. on the relationship between logistics supply side and demand side. In particular, there are also few studies on logistics resources integration from the cooperative game.

This paper gives the connotation of the steel logistics resource integration, analyzes steel logistics resource integration based on cooperative game and proposes benefit distribution mechanism of steel logistics resources integration.

\section{ANALYSIS OF THE CONNOTATION OF STEEL LOGISTICS RESOURCES INTEGRAION}

\subsection{Classification of Steel Logistics Resources}

Logistics resources are production factors that logistics enterprises provide valuable logistics service for customers. There are more classification standards of logistics resources. For example, there are internal and external logistics resources, customer resources, ability resources and information resources [13]. 
Logistics resources has its particularity in the steel supply chain. In steel logistics supply chain, some nodes can both provide logistics service and demand logistics service in some cases. For example, steel production enterprises provide logistics services for downstream customers in steel supply chain by using storage resources and transportation resources. On the other hand, steel production enterprises outsource a part of logistics to the third logistics company. Therefore, steel logistics resources not only include the logistics resources of logistics services provider, but also include logistics resources of logistics demander. Steel logistics resources from both sides should be unified logistics supply-demand network.

In the aspect of content, according to logistics network theory, logistics network is developed to meet the demand of logistics systematization and standardization and includes three organic parts of logistics organization network, logistics infrastructure network and logistics information network that forms the modern logistics service network system [14]. And then the steel logistics resources can be divided into the steel logistics infrastructure resources, steel logistics organization resources, steel logistics information resources.

\subsection{Characteristic of Steel Logistics Resources}

Comparing with general logistics resources, the steel logistics resource has the particularity.

\section{(1) Ownership Diversity}

In the steel supply chain, the owners of logistics resources not only include logistics service provider, but also include logistics service demander, such as steel production enterprises, steel trading enterprises, steel logistics enterprises.

\section{(2) Regional Aggregation}

In China, steel production and sales has regional. The distribution of steel logistics resources often relies on steel production and sales. Steel logistics resources gather around the steel production enterprises and sales enterprises. For example, large-scale logistics parks are constructed around the steel production and sales enterprises. In the logistics parks, there are a large number of transport vehicles, storage facilities and logistics enterprises.

\section{(3) Fusion}

The steel logistics resources penetrate the steel supply chain. The logistics supply side and logistics demand side are in one network. One supply chain can form by integrating. Each supply chain is not only product supply chain but also steel logistics service supply chain. It fully reflects the fusion of product supply chain and logistics service supply chain.

\subsection{Connation of Steel Logistics Resources Integration}

Based on the above analysis, this paper proposes the connotation of steel logistics resource integration based on the perspective of supply-demand relationship of steel logistics, which is integrating supply organization and demand organization of steel logistics service as a whole network, restructuring and optimizing allocation of steel logistics resources by the means of constructing steel logistics service supply chain, and integrating steel logistics service supply chain and steel products supply chain into an integrated steel supply chain to meet the demand of steel logistics user and achieve linkage and win-win goal of supply organization and demand organization of steel logistics.

\section{BENEFIT DISTRIBUTION MECHANISM OF STEEL LOGISTICS RESOURCES INTEGRATION}

\subsection{Analysis of Steel Logistics Resources Integration Based on Cooperation Game}

According to the cooperative game theory, decision makers obtain the greatest possible benefits by working together. The game is a macroscopic angle. In a cooperative game, the decision makers consider establishment of alliance and benefits distribution. Cooperative game theory provides a systemic method to study benefit coexistence strategy. The core problem of cooperative game is how to make all the people involved in the alliance to obtain the benefits as large as possible and how to allocate the benefits. Cooperative game theory can make the optimal decision help enterprises solve the problems in the cooperation and truly realize the "winwin"[15].

Steel logistics resources integration is a process in which three parts including supply node, demand node and dual attribute node interact and the scattered steel logistics resources are dynamically restructured and allocated. Through the steel logistics resources integration, on one hand, the steel logistics supply organization enhances the capacity of steel logistics service; on the other hand, the demand of steel logistics user can be met. And this promotes the linkage and win-win of logistics service supply organization and demand organization. The process of steel logistics resources integration is process of constructing steel logistics service supply chain. The fundamental purpose of logistics resources integration is to achieve the maximum economic benefits for all parties on steel logistics service supply chain. The relationship of parties on steel logistics service supply chain is cooperative game. Reasonable benefit allocation mechanism is the prerequisite for steel logistics resources integration.

\subsection{The Principles of Benefit Distribution in Steel Logis- tics Resources Integration}

The benefit distribution in steel logistics resources integration should insist on the following several aspects of the principles.

\section{(1) The Balance of Risks and Benefits}

The enterprises which undertake greater risks should be given compensation in order to enhance the enthusiasm of cooperation. But the size of evaluation of risk is very complex, especially when the benefit distribution scheme determined in advance.

\section{(2) Win-Win}

The benefit distribution must ensure that all enterprises participating logistics resources integration can benefit and the benefits are not less than the contributions to the steel logistics service supply chain.

(3) Structure Optimization of Benefit 
The optimal structure of benefit distribution should be reasonably determined according to the objective and influence factors of steel logistics resources integration, so that the joint enterprise can achieve the best cooperation and coordinated development.

\subsection{The Influence Factors of Benefit Distribution in Steel Logistics Resources Integration}

Steel logistics resources integration is process of constructing steel logistics service supply chain according to the logistics demand of customer. In this process, the scattered steel logistics resources from supply node and demand node are dynamically restructured and allocated. Especially, the capacity of steel logistics service is enhanced and benefits for both sides of supply and demand of steel logistics service are created. By the analysis of steel logistics resources integration, there are several influence factors of benefit distribution as follows.

\section{(1) Input of Steel Logistics Resources}

The final result of steel logistics resources integration is the formation of the steel logistics service supply chain. The steel logistics service supply chain is essentially a valueadded chain. Through cooperation of steel logistics integrator and function of business open and share logistics resources, provide a full range of integrated logistics services for the customers. The participating parties in the steel logistics resources integration are cooperative relations based on the resources. Resource is a basic condition of steel logistics service supply chain and an important factor in determining benefit distribution. Therefore, the benefit distribution in steel logistics resources integration should be integrated into the input level logistics resources of all parties involved in steel logistics resource integration. The connotation of resource is very rich. According to the analysis of the 2.1 quarter, the steel logistics resources include logistics infrastructure resources, logistics organization resources and logistics information resources of the supply side and demand side of steel logistics services. The key of implementation of the allocation to resources base is the value of input logistics resource in the steel logistics service supply chain. For the elements of steel logistics resources, not only to consider the cost value, more to consider its resource value in the whole steel logistics service supply chain.

\section{(2) The Ability of Risk-taking}

The benefit distribution must ensure that all enterprises participating logistics resources integration can benefit and the benefits are not less than the contributions to the steel logistics service supply chain. Therefore, the ability of risktaking of all parties which join steel logistics resources integration should be taken into the consideration of benefit distribution. The enterprises which undertake greater risks should be given compensation so that this benefit distribution is more reasonable.

\section{(3) Logistics Service Quality}

An important objective of the steel logistics resources integration is to provide satisfactory logistics services for the customers according to the various demands of the customers. In the steel logistics service supply chain, logistics service is the core product of supply chain. The quality of logis- tics service is an important evaluation index of the logistics resources integration evaluation. If there is a gap between the logistics service quality and customer expectations, the customer will be disappointed. Accordingly, it will affect the benefit. And also it is the determining factor of benefit in logistics resources integration. Therefore, the logistics service quality is one of the important factors that influence the benefit distribution in steel logistics resources integration.

\subsection{Benefit Distribution Model Based on Shapley Value}

In the beginning stage of steel logistics integration, a reasonable benefit distribution scheme can make all parties on steel logistics service supply chain reach an agreement and smooth promotion. The essence of benefit distribution in steel logistics integration is a negotiation process of multiperson cooperative game.

In the numerous relevant benefit distribution schemes, the Shapley value method is more appropriate to solve the multi-person cooperative game problem. Shapley value method is proposed by Shapley [16]. It is a mathematical solution for cooperative games on multi-person. When cooperation alliance achieves the greatest benefit in cooperative relationship composed of several enterprises, the enterprises are willing to cooperate and pay more attention to benefit distribution. Shapley value method gives a more equitable distribution scheme, and it is widely used in the calculation of benefit distribution. Shapley value method is based on the current benefit of all participates. When $n$ subjects achieve maximum benefit through cooperation, the Shapley value method can determine how to distribute the maximum benefits in every subject.

The process of Shapley value method is as follows.

Set $I=\{1,2, \ldots, n\}$ is composed of $\mathrm{n}$ subjects.

$I$ is composed of $n$ subjects. $S$ is a subset of $I$. The function $v(s)$ represents the benefit of $s$, and meets the following conditions.

$$
\begin{aligned}
& v(\phi)=0 \\
& v\left(s_{1} \cup s_{2}\right) \geq v\left(s_{1}\right)+v\left(s_{2}\right) \\
& s_{1} \cap s_{2}=\phi, s_{1} \subseteq I, s_{2} \subseteq I
\end{aligned}
$$

$[I, v]$ is $n$ subjects cooperative game. $V$ is the characteristic function of game. The significance of the function is that cooperation gains more than their own independent action.

Let $x_{i}$ denote benefit of $i$ in the $I$ subjects from the maximum cooperation benefit $v(I) . x=\left\{x_{1}, x_{2}, \ldots, x_{n}\right\}$ denotes distribution of cooperative game. The success cooperative game should meet the following conditions.

$$
\begin{aligned}
& \sum_{i=1}^{n} x_{i}=v(I) \\
& x_{i} \geq v(I), i=1,2,3, \ldots, n
\end{aligned}
$$

That means cooperation benefit of $\mathrm{n}$ subjects is no less than their own independent action.

Then the Shapley value under the cooperation $I$ is 
$\phi(v)=\left[\varphi_{1}(v), \varphi_{2}(v), \ldots, \varphi_{n}(v)\right]$

$\varphi_{i}(v)=\sum_{s \subseteq s_{i}} \omega(|s|)[v(s)-v(s \backslash i)]$,

$i=1,2, \ldots, n$

$\omega(s)=\frac{(n-|s|) !(|s|-1) !}{n !}$

In the above formula, $\varphi_{i}(v)$ is the benefit of subject $i$ under the cooperation $I . S_{i}$ is all subsets containing subject $i$ in set $I .|s|$ is the number of elements in subset s. $\omega(|s|)$ is weighted factor. $v(s)$ is the benefit of subset $s . v(s \mid i)$ is the benefit of subset $s$ in which removes subject $i$.

In benefit distribution of steel logistics resources integration, $I$ can be regarded as a set of component of each enterprise in the steel logistics supply and demand network. $s$ is the subset which composed of all enterprises in steel logistics resources integration. $v(s)$ is the benefit of subset $s$ in steel logistics resources integration. $v(s \mid i)$ is the benefit of subset $s$ when subject $i$ don't join steel logistics resources integration. Through this method, reasonable benefit distribution of steel logistics resources integration can be achieved. In the next part, a case study will be proposed to verify the feasibility of this method.

\section{CASE STUDY}

$\mathrm{H}$ Steel Group is one of the largest steel enterprises in China. H Steel Group has established the electronic trading platform in 2013. The electronic trading platform integrates steel production enterprises, steel trade enterprises, steel logistics enterprises and many other organizations. These enterprises build a steel logistics supply-demand network.

The steel production enterprises belong to H Steel Group. The majority of these steel enterprises have built their owned warehouse in the factory and steel logistics parks in the port. There is a large number of logistics demand. The majority of these steel enterprises have built their owned warehouse in the factory and steel logistics parks in the port.

This electronic trading platform is a typical example of steel logistics resources integration.

The steel logistics resources of the supply and demand parties achieve the effective integration and sharing in the platform. Through this platform, when users finished steel transactions, they can also select the appropriate logistics service independently according to their own needs. And then the logistics service provider based on user requirements complete logistics services through cooperative operation and sharing of logistics resources. The keys are supply and demand information matching online and collaborative operation offline.

Every logistics service in the platform is an operation of steel logistics service supply chain. This electronic trading platform creates benefit for all parties and realizes the logistics service supply and demand sides win-win.

After completion of purchasing in the electronic trading platform, the customer will select the logistics service. A, B and $\mathrm{C}$ are three enterprises with different logistics resources and service capacity. The three enterprises form steel logistics service supply chain through the logistics resources integration. Three enterprises jointly provide logistics service for customers.

The benefits of three enterprises are 5 million yuan, 3 million yuan, 3 million yuan be before the integration. The total benefits of three enterprises are 20 million yuan after be before the integration. When $\mathrm{A}$ and $\mathrm{B}$ are integrated, the benefit is 12 million yuan. When $\mathrm{A}$ and $\mathrm{C}$ are integrated, the benefit is 15 million yuan. When $\mathrm{B}$ and $\mathrm{C}$ are integrated, the benefit is 12 million yuan. According to the Shapley value method, the benefits of $\mathrm{A}, \mathrm{B}$ and $\mathrm{C}$ can be caculated by adding the last line in Tables 1-3. the benefits of $\mathrm{A}, \mathrm{B}$ and $\mathrm{C}$ are 47/6 million yuan, 32/6 million yuan and 41/6 million yuan. Obviously, The benefit of integrating three enterprises is more than the benefit of integrating a single enterprise or double enterprises.

\section{CONCLUSION}

At present, there are some outstanding problems in steel industry, such as steel production capacity surplus, supplydemand contradiction. Therefore, the steel logistics industry has been impacted. The scattered and closed steel logistics resource should be integrated. Reasonable benefit allocation mechanism is the prerequisite for steel logistics resources integration.

Based on previous studies on steel logistics resource integration, this paper proposes an important problem in steel logistics resources integration: benefit distribution.

Table 1. The benefit distribution of $A$.

\begin{tabular}{|c|c|c|c|c|}
\hline $\mathbf{s}_{\mathbf{1}}$ & $\mathbf{1}$ & $\mathbf{1} \bigcup_{\mathbf{2}}$ & $\mathbf{1} \bigcup_{\mathbf{3}}$ & $\mathbf{1} \bigcup_{\mathbf{3}}$ \\
\hline \hline $\mathrm{v}(\mathrm{s})$ & 5 & 12 & 15 & 20 \\
\hline $\mathrm{v}(\mathrm{s} \backslash 1)$ & 0 & 3 & 3 & 12 \\
\hline $\mathrm{v}(\mathrm{s})-\mathrm{v}(\mathrm{s} \backslash 1)$ & 5 & 9 & 2 & 3 \\
\hline$|\mathrm{s}|$ & 1 & 2 & $1 / 6$ & $1 / 3$ \\
\hline$\omega(|\mathrm{s}|)$ & $1 / 3$ & $3 / 2$ & 2 & $8 / 3$ \\
\hline$\omega(\mid \mathrm{s})[\mathrm{v}(\mathrm{s})-\mathrm{v}(\mathrm{s} \backslash 1)]$ & $5 / 3$ & & & \\
\hline
\end{tabular}


Table 2. The benefit distribution of $B$.

\begin{tabular}{|c|c|c|c|c|}
\hline $\mathbf{s}_{\mathbf{2}}$ & $\mathbf{2}$ & $\mathbf{1} \bigcup_{\mathbf{2}}$ & $\mathbf{2} \mathbf{3}_{\mathbf{3}}$ & $\mathbf{1} \bigcup_{\mathbf{3}}$ \\
\hline \hline $\mathrm{v}(\mathrm{s})$ & 3 & 12 & 3 & 20 \\
\hline $\mathrm{v}(\mathrm{s} \mid 2)$ & 0 & 5 & 9 & 5 \\
\hline $\mathrm{v}(\mathrm{s})-\mathrm{v}(\mathrm{s} \mid 2)$ & 3 & 7 & 2 & 3 \\
\hline$|\mathrm{s}|$ & 1 & $1 / 6$ & $1 / 6$ & $1 / 3$ \\
\hline$\omega(|\mathrm{s}|)$ & 1 & $7 / 6$ & $3 / 2$ & $5 / 3$ \\
\hline$\omega(|\mathrm{s}|)[\mathrm{v}(\mathrm{s})-\mathrm{v}(\mathrm{s} \mid 2)]$ & & & & 5 \\
\hline
\end{tabular}

Table 3. The benefit distribution of $\mathrm{C}$.

\begin{tabular}{|c|c|c|c|c|}
\hline $\mathbf{s}_{\mathbf{3}}$ & $\mathbf{3}$ & $\mathbf{1} \bigcup_{\mathbf{3}}$ & $\mathbf{2} \mathbf{3}_{\mathbf{3}}$ & $\mathbf{1} \bigcup_{\mathbf{3}}$ \\
\hline \hline $\mathrm{v}(\mathrm{s})$ & 3 & 15 & 3 & 12 \\
\hline $\mathrm{v}(\mathrm{s} \mid 3)$ & 0 & 5 & 9 & 8 \\
\hline $\mathrm{v}(\mathrm{s})-\mathrm{v}(\mathrm{s} \mid 3)$ & 3 & 10 & 2 & 3 \\
\hline$|\mathrm{s}|$ & 1 & 2 & $1 / 6$ & $1 / 3$ \\
\hline$\omega(|\mathrm{s}|)$ & $1 / 3$ & $5 / 3$ & $3 / 2$ & $8 / 3$ \\
\hline$\omega(|\mathrm{s}|)[\mathrm{v}(\mathrm{s})-\mathrm{v}(\mathrm{s} \mid 3)]$ & 1 & $1 / 6$ & \\
\hline
\end{tabular}

First, this paper gives the classification of steel logistics resources based on logistics network theory and the particularity of logistics resources in the steel supply chain, analyzes the characteristic of steel logistics resources, and proposes connotation of steel logistics resources integration, which is integrating supply organization and demand organization of steel logistics service as a whole network, restructuring and optimizing allocation of steel logistics resources by the means of constructing steel logistics service supply chain, and integrating steel logistics service supply chain and steel products supply chain into an integrated steel supply chain.

Second, this paper gives analysis of steel logistics resources integration based on cooperation game, proposes the three principles(balance of risks and benefits, win-win and structure optimization of benefit) and three influence factors(input of steel logistics resources, ability of risktaking and logistics service quality), establishes benefit distribution model based on Shapley value.

At last, This paper verifies the feasibility of the above theory and the method by a case study.

In the further studies, more factors of benefit distribution in steel logistics resources integration will be taken into cosideration. The model will be improved. The other operation mechanisms will be studies, such as matching mechanisms of task and resource, Task coordination mechanisms.

\section{CONFLICT OF INTEREST}

The authors confirm that this article content has no conflict of interest.

\section{ACKNOWLEDGEMENTS}

This paper was supported by the National Natural Science Foundation of China (Grant No. 71372013).

\section{REFERENCES}

[1] X. Cui, C. Zhang, and J. Wang, "Logistics resources integration in Hefei economic circle based on industrial cluster," Journal of Hefei University: Social Sciences, vol. 31, no. 1, pp. 39-42, 2014.

[2] B. Sui, and Y. Fu, "The research on logistics resources integration in Beibu Gulf economic zone," Journal of Qinzhou University, vol. 29, no. 5, pp. 29-32, 2014.

[3] L. Dong, and X. Qu, "Research on logistics resources integration cooperation and maritime transport and logistics in Tumen river zone," Economic Review, no. 2, pp. 48-51, 2011.

[4] S. Tian, X. Wang, and Z. Wang, "Decision analysis of logistics resources integration based on maximum utility of customer," Computer Engineering and Applications, vol. 48, no. 23, pp.203206, 2012.

[5] Z. Song, Q. Zhao, "A study on logistics resource integration in manufacturing group," Journal of Beijing Jiaotong University Social Sciences Edition, vol. 13, no. 2, pp.1-7, 2014.

[6] Y. Jin, "An improved profit distribution model for iron and steel logistics alliance," Advances in Information Sciences and Service Sciences, vol. 4, no. 3, pp. 159-166, 2012.

[7] T. Huth, and C. M. Dirk, "Integration of vehicle routing and resource allocation in a dynamic logistics network," Transportation Research Part C: Emerging Technologies, vol. 17, no. 2, pp. 149162, 2009.

[8] J. Yao, "Decision Optimization Analysis on Supply Chain Resource Integration in Fourth Party Logistics," Journal of Manufacturing Systems, vol. 29, no. 4, pp. 121-129, 2010.

[9] W. Li, "Giving full play to regional advantages to integrate resources effectively and enhance extension service capacity of steel supply chain," Railway Purchase and Logistics, vol. 4, pp. 61-63, 2013. 
[10] R. Jia, "A study on service supply chain agility of steel logistics based on supply-hub," Huazhong University of Science and Technology, 2011.

[11] G. Jin, "Research of steel logistics based on supply chain collaboration," Logistics Engineering and Management, vol. 36, no. 9, pp. 136-138, 2014

[12] F. Xiong, Q. Cao, and Y. Huang, "Research of cloud business platform in the steel industry chain," Key Engineering Materials, vol. 522, pp. 783-787, 2012.
[13] W. Xia, "Research on the theory and application of railway logistics resources integration and optimization," Central South University, 2010

[14] S. Ju, J. Xu, and W. Bian, "Putting Forward and Research on Logistics Network Theory", Journal of Beijing Jiaotong University Social Sciences Edition, vol. 4, pp. 22-26, 2005.

[15] C. Tan, and Q. Zhang, "Cooperative game theory and Application," Science Press, 2011.

[16] E. R. Alvin, "The Shapley Value: Essays in Honorof Lloyd S Shapley," Cambridge University Press, 1989.

(C) Yuqing and Songdong; Licensee Bentham Open.

This is an open access article licensed under the terms of the Creative Commons Attribution Non-Commercial License (http://creativecommons.org/licenses/by-nc/3.0/) which permits unrestricted, non-commercial use, distribution and reproduction in any medium, provided the work is properly cited. 